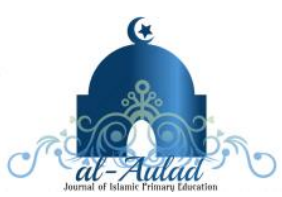

\title{
PENGARUH BAHAN AJAR BERBASIS LITERASI DENGAN PENDEKATAN KONTEKSTUAL TERHADAP HASIL BELAJAR SISWA SEKOLAH DASAR
}

\author{
Ari Metalin Ika Puspita ${ }^{1}$, Suciati Purwo ${ }^{2}$ \\ ${ }^{1 ’ 2}$ Program Studi Pendidikan Guru Sekolah Dasar STKIP PGRI Trenggalek \\ arimetalinikapuspita2@gmail.com \\ Naskah diterima: 1 Februari, 2019, direvisi: 1 Maret, 2019, diterbitkan: 31 Maret, 2019
}

\begin{abstract}
The purpose of this study was to see the effect of the application of literacy based thematic teaching materials with a contextual approach to student learning outcomes. The method used in this study is a type of quantitative research. The research design used in this study was Quasi Experimental Design with the form of Nonequivalent Control Group Design. In the design of this study researchers used one experimental group with a control group that began with the pretest in each group. The results of this study found that the use of thematic teaching materials had a significant effect on student learning outcomes. Contextual based thematic teaching materials with a literacy approach can be used as supporting teaching materials in addition to the main teaching material.
\end{abstract}

Keywords: Teaching Materials, Based on Literacy, Learning Outcomes, Contextual Approaches

\begin{abstract}
ABSTRAK
Tujuan penelitian ini adalah untuk melihat pengaruh penerapan bahan ajar tematik berbasis literasi dengan pendekatan kontekstual terhadap hasil belajar siswa. Metode yang digunakan dalam penelitian ini adalah jenis penelitian kuantiatif. Desain penelitian yang digunakan dalam penelitian ini adalah Quasi Experimental Design dengan bentuk Nonequivalent Control Group Design. Pada rancangan penelitian ini peneliti menggunakan satu kelompok eksperimen dengan kelompok kontrol yang diawali dengan pemberian pretest pada masing-masing kelompok. Hasil penelitian ini diperoleh bahwa penggunaan bahan ajar tematik ini berpengaruh signifikan terhadap hasil belajar siswa. Bahan ajar tematik berbasis kontekstual dengan pendekatan literasi dapat digunakan sebagai bahan ajar penunjang disamping bahan ajar utama.
\end{abstract}

Kata Kunci: Bahan Ajar, Berbasis Literasi, Hasil Belajar, Pendekatan Kontekstual

\section{PENDAHULUAN}

Pendidikan memegang peranan yang pertama dan utama dalam kemajuan bangsa dan Negara Indonesia. Pendidikan yang bermutu akan menghasilkan sumber daya manusia yang berkompeten di segala bidang. Pembelajaran di sekolah dasar merupakan dasar untuk mengembangkan potensi peserta didik ke jenjang berikutnya sehingga diperlukan stimulus serta rangsangan agar kompetensi yang ada dalam diri siswa dapat berkembang dengan baik (Puspita: 2016). Kompetensi tersebut harus dikembangkan mulai dari pendidikan dasar. Salah Satu kompetensi yang harus dikembangkan sejak pendidikan dasar yaitu keterampilan literasi.

Literasi merupakan keterampilan penting yang harus dimiliki oleh setiap siswa. Sebagian besar proses pendidikan bergantung pada kemampuan dan kesadaran literasi. Kemendikbud (2016) menyatakan "literasi adalah kemampuan mengakses, memahami, dan menggunakan sesuatu secara cerdas melalui berbagai aktivitas, antara lain membaca, melihat, menyimak, menulis, dan/atau berbicara." Dalam pembelajaran, kemampuan ini 
merupakan langkah awal yang sangat penting dalam keberhasilan proses pembelajaran yang produktif dikarenakan dengan kemampuan literasi yang baik siswa memiliki daya serap yang baik terhadap informasi yang diperolehnya sehingga dapat menghasilkan gagasangagasan dan karya. Oleh karena itu, dalam pembelajaran bahasa Indonesia khususnya pembelajaran apresiasi sastra anak harus dirancang dan dilaksanakan dengan mengintegrasikan keterampilan literasi dan menggunakan bahan ajar yang mampu melatih siswa untuk terampil dalam membaca, menulis, menyimak, berbicara, dan memilah informasi.

Bahan ajar merupakan segala bahan yang disusun secara sistematis mencakup kompetensi yang akan dikuasai siswa dan digunakan dalam proses pembelajaran dengan tujuan perencanaan dan penelaahan implementasi pembelajaran (Prastowo: 2012). Seluruh kompetensi yang dimaksud tersebut, tercantum dalam Kurikulum 2013 yang saat ini digunakan di Indonesia. Bahan ajar menjadi penentu keberhasilan tujuan pendidikan. Bahan ajar yang baik adalah bahan ajar yang mampu membantu siswa untuk memahami materi yang disampaikan oleh guru (Puspita: 2017). Sedangkan Panen (2001) mengungkapkan bahwa bahan ajar merupakan bahan-bahan atau materi pelajaran yang disusun secara sistematis, yang digunakan guru dan peserta didik dalam proses pembelajaran. Sehingga dapat disimpulkan bahawa bahan ajar merupakan alat yang digunkan guru dalam proses pembelajaran yang berisi materi pembelajaran yang disampaikan secara sistematis yang bertujuan untuk meningkatkan kompetensi siswa.

Bahan ajar yang baik disusun berdasarkan lingkungan belajar siswa. Materi yang berdasarkan lingkungan belajar akan mampu menimbulkan kebermaknaan di dalam proses pembelajaran. Jhonson (2008) mengatakan bahwa Pendekatan Kontesktual merupakan sebuah sistem yang menyeluruh yang terdiri dari bagian-bagian yang saling berhubungan. Sehingga Jika bagian-bagian ini dapat terjalin serta terhubung satu sama lain, maka akan dihasilkan suatu pengaruh yang akan melebihi hasil yang diberikan bagian-bagian secara terpisah. Sedangkan Puspita (2018) menyatakan bahwa pendekatan kontekstual merupakan pendekatan yang melibatkan pengalaman individu untuk mendapatkan pengetahuan baru, berbagai informasi, dan aplikasi pengetahuan di dalam kehidupan. Sehingga manfaat pendekatan kontekstual memegang peranan yang fundamental, apalagi kurikulum 2013 yang berlaku saat ini menuntut siswa untuk mampu berfikir konstruktivistik dan sainstifik.

\section{METODOLOGI}

Model penelitian yang digunakan adalah model penelitian kuantitatif dengan metode eksperimen. Metode eksperimen adalah metode penelitian yang digunakan untuk mencari pengaruh perlakuan tertentu terhadap yang lain dalam kondisi yang terkendalikan (Sugiyono, 2014:107). Desain penelitian yang digunakan dalam penelitian ini adalah Quasi Experimental Design dengan bentuk Nonequivalent Control Group Design. Pada rancangan penelitian ini peneliti menggunakan satu kelompok eksperimen dengan kelompok kontrol yang diawali dengan pemberian pretest pada masing-masing kelompok. Kelompok eksperimen diberikan perlakuan sedangkan kelompok kontrol tidak diberikan perlakuan. Pada akhir penelitian akan diberikan posttest kepada kedua kelompok tersebut. Rancangan Penelitian ditunjukkan pada Gambar berikut. 


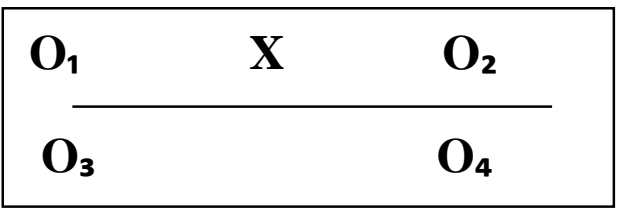

Gambar 1 Rancangan Penelitian

Teknik pengumpulan data pada penelitian ini menggunakan observasi dan tes. Metode observasi digunakan untuk mengetahui data penggunaan bahan ajar berbasis literasi dengan pendekatan kontekstual di dalam pembelajaran sastra anak di Kelas IV. Pengambilan data prestasi belajar siswa menggunakan tes. Tes ini dilakukan agar peneliti mengetahui hasil belajar siswa setelah menggunakan bahan ajar yang sudah digunakan.

\section{HASIL DAN DISKUSI}

Pada uji coba bahan ajar tematik berbasis literasi dengan pendekatan kontekstual akan melihat pengaruh pengaruh bahan ajar terhadap hasil belajar siswa dengan memberikan soalsoal evaluasi diakhir penggunaan bahan ajar. Berdasarkan uji coba bahan ajar diperoleh Hasil Belajar Siswa di SDN I Surodakan, SDN 2 Surodakan, SDN I Ngares, SDN II Ngares, SDN I Karangan, dan SDN II Karangan diperoleh rentang nilai hasil belajar siswa yang disajikan pada 1 berikut.

Tabel 1 Nilai Hasil Belajar Siswa

\begin{tabular}{cccc}
\hline No. & Rentang Nilai & Frekuensi & Persentase (\%) \\
\hline $\mathbf{1}$ & $91-100$ & 31 & 37,34 \\
\hline $\mathbf{2}$ & $81-90$ & 36 & 43,37 \\
\hline $\mathbf{3}$ & $71-80$ & 8 & 9,63 \\
\hline $\mathbf{4}$ & $61-70$ & 5 & 6,02 \\
\hline $\mathbf{5}$ & $00-51$ & 2 & 2,4 \\
\hline Jumlah & & 83 & 100 \\
\hline
\end{tabular}

Berdasarkan Tabel 1 data yang didapat dari hasil belajar siswa yaitu siswa yang memperoleh nilai 91-100 sebanyak 31 siswa atau 37,34 \%. Kemudian siswa yang memperoleh nilai 81-90 sebanyak 36 siswa atau 43,37\%. Sedangkan sebanyak 8 siswa atau 9,63\% mendapatkan rentang nilai 71-80 dan siswa yang memperoleh rentang nilai 61-70 sebanyak 5 siswa atau 6,02\% serta 2,4\% siswa memperoleh rentang nilai 00-51. Perbedaan persentase nilai yang didapat oleh siswa dapat dilihat pada Gambar 1 Diagram Lingkaran Hasil Belajar berikut: 


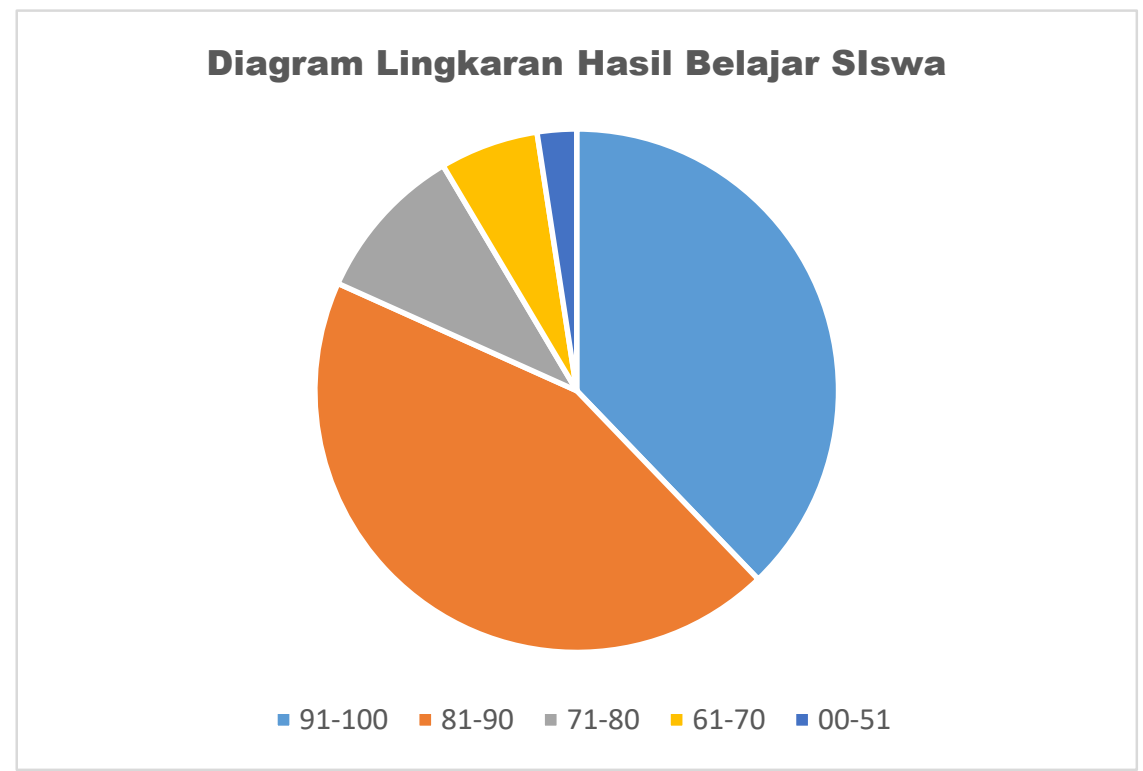

Gambar 1 Diagram Lingkaran Hasil Belajar Siswa

Sebelum menguji pengaruh penggunaan bahan ajar berbasis lietrasi dengan pendekatan kontekstual harus melakukan uji normalitas dan uji homogenitas. Uji Normalitas ditunjukkan pada Tabel berikut.

Tabel 2 Uji Normalitas Hasil Belajar

\begin{tabular}{lllllll}
\hline & \multicolumn{7}{c}{ Kolmogorov-Smirnov ${ }^{\mathrm{a}}$ Shapiro-Wilk } \\
\cline { 2 - 7 } & Statistic & Df & Sig. & Statistic & Df & Sig. \\
\hline hasil_belajar & .231 & 37 & .002 & .819 & 37 & .002 \\
\hline
\end{tabular}

a. Lilliefors Significance Correction

Berdasarkan Tabel 2 hasil uji normalitas dengan menggunakan formula kolmogorovsmirnov diketahui bahwa data hasil belajar sebelum menggunakan bahan ajar tematik berbasis literasi dengan pendekatan kontekstual tidak berdistribusi normal karena nilai signifikansinya dibawah $0,05(0,001<0,05)$. Data hasil belajar sesudah menggunakan bahan ajar juga tidak berdistribusi normal, hal ini ditunjukkan dari nilai signifikansinya yang berada di bawah $0,05(0,000<0,02)$. Jadi dapat disimpulkan bahwa data tersebut tidak berdistribusi normal.

Sedangkan hasil Uji Homogenitas hasil belajar ditunjukkan pada Tabel 3 berikut. 
Tabel 3 Uji Homogenitas Hasil Belajar

\begin{tabular}{|c|c|c|c|c|c|}
\hline & & $\begin{array}{l}\text { Levene } \\
\text { Statistic }\end{array}$ & df1 & df2 & Sig. \\
\hline \multirow[t]{4}{*}{ hasil_belajar } & Based on Mean & 2.070 & 1 & 86 & .203 \\
\hline & Based on Median & 1.524 & 1 & 86 & .220 \\
\hline & $\begin{array}{l}\text { Based on Median and } \\
\text { with adjusted df }\end{array}$ & 1.524 & 1 & 79.469 & .221 \\
\hline & Based on trimmed mean & 2.011 & 1 & 86 & .160 \\
\hline
\end{tabular}

Berdasarkan Tabel 3 Dari uji homogenitas hasil belajar sebelum dan sesudah dengan statistic based on mean diperoleh nilai signifikansi 0,203. Hal ini menunjukkan bahwa nilai signifikansi lebih dari 0,05, maka data penelitian tersebut homogen.

Tes hasil belajar yang dilakukan untuk menguji hiptesis disajikan pada Tabel 4 berikut.

Tabel 4 Hasil Uji Hipotesis Hasil Belajar Siswa Test Statistics ${ }^{\mathrm{b}}$

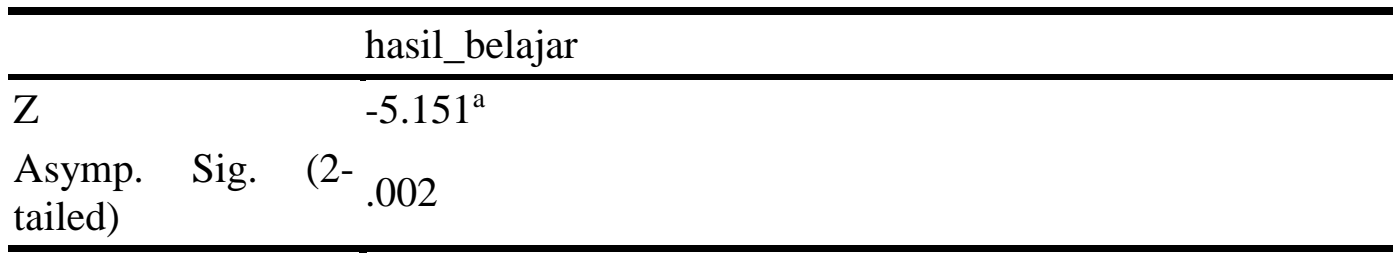

a. Based on negative ranks.

b. Wilcoxon Signed Ranks Test

Berdasarkan Tabel 4 dari hasil uji komparasi dengan formula wilcoxon diperoleh nilai signifikansi 0,002 $(<0,05)$. Hasil tersebut menunjukkan bahwa ada perbedaan antara hasil belajar sebelum dan sesudah menggunakan bahan ajar tematik berbasis lietrasi dengan pendekatan kontekstual

Penggunaan Bahan Ajar Tematik berbasis lietrasi dengan pendekatan kontekstual berpengaruh terhadap hasil belajar siswa. Hal tersebut dapat dilihat bahwa nilai siswa sebelum dan sesudah menggunakan bahan ajar berbeda. Siswa kelas IV di SDN 1 dan SDN 2 Surodakan yang digunakan sebagai uji coba lapangan dapat dilihat peningkatan hasil belajar siswa ssetelah menggunakan bahan ajar tersebut.

Kemudian angket respon siswa setelah menggunakan bahan ajar bahwa siswa merasa sakit tertarik terhadap konten bahan ajar, isinya mudah dipahami, tidak merasa bosan, dan membuat siswa semangat. Kemudian dari aspek praktisi memberikan komentar bahwa bahan ajar tematik berbasis kontekstual dengan pendekatan literasi dapat digunakan sebagai bahan ajar penunjang untuk meningkatkan hasil belajar siswa. Guru sangat terbantu dengan penggunaan bahan ajar tersebut karena penyusunan materi disesuaikan dengan lingkungan belajar siswa, sehingga siswa mudah memahami materi yang diajarkan oleh guru.

\section{KESIMPULAN}

Bahan ajar tematik berbasis lietrasi dengan pendekatan kontekstual dikembangkan berdasarkan analisis kebutuhan, lingkungan belajar, dan karakteristik siswa. Pengambangan bahan ajar ini dengan memasukkan beberapa materi yaitu dari segi sejarah, makanan khas, ekonomi, dan pekerjaan. 
Bahan ajar yang digunakan di dalam proses pembelajaran mempunyai pengaruh signifikan terhadap hasil belajar siswa. Sehingga setelah menggunakan bahan ajar, hasil belajar siswa mempunyai perbedaan sebelum dan sesudah menggunakan bahan ajar. Bahan ajar ini sangat sesuai digunakan sebagai bahan ajar penunjang di dalam proses pembelajaran.

Pengembangan bahan ajar sangat dibutuhkan agar siswa mempunyai pengetahuan luas dan mampu merangsang pola pikir siswa untuk menjadi generasi milineal. Serta penyusunan materi di dalam bahan ajar sebaiknya dari lingkungan terdekat siswa ke lingkup yang lebih luas.

\section{ACKNOWLEDGMENT}

Penelitian ini didukung oleh Direktorat Jenderal Riset Penguatan Riset dan Pengembangan Kementerian Riset, Teknologi, dan Pendidikan Tinggi melalui skema Penelitian Dosen Pemula (PDP) Tahun 2017

\section{DAFTAR PUSTAKA}

Arikunto, S. (2009). Prosedur Penelitian Suatu Pendekatan Praktik. Jakarta: Rineka Cipta.

Bahtiar, Reza Syehma. (2016). Pengaruh Desain Pembelajaran Assure Terhadap Hasil Belajar Siswa Sekolah Dasar. Jurnal Inovasi Vol. 18, No. 1. Januari 2016, hal 4449.

Departemen Pendidikan Nasional. (2008). Pengembangan Bahan Ajar dan Media. Jakarta:Depdiknas.

Hamalik, Oemar. (2011). Proses Belajar Mengajar. Jakarta:Bumi Aksara.

Hayat, B. \& Yusuf, S. (2010). Benchmark Internasional Mutu Pendidikan. Jakarta: Bumi Aksara.

Irwandi. (2013). Pengaruh Pendekatan Kontekstual Terhadap Hasil Belajar Biologi Siswa SMA. Jurnal Ilmu Pendidikan Vol. 19, No. 1, Juni 2013, hal 100-105.

Iskandarwassid, dan Sunendar, Dadang. (2011). Strategi Pembelajaran Bahasa. Bandung: PT Remaja Rosdakarya.

Jhonson, Elanie. B. (2008). Contextual Teaching \& Learning. Bandung: Mizan Learning Center

Komalasari, Kokom. (2011). Pembelajaran Kontekstual. Bandung : PT. Refika Aditama.

Maduriana, I Made dan Seniwati, Ni Putu. (2015). Pengembangan Bahan Ajar IPA SD Bermuatan Pendidikan Karakter Berbasis Tradisi Lisan Bali. Jurnal Kajian Bali Vol. 5, No. 2, Oktober 2015, hal 369-390.

Musfroh, Tadkiroatun, dan Listyorini, Beniati. (2016). Konstruk Kompetensi Literasi untuk Siswa Sekolah Dasar. Jurnal Litera Vol. 15, No. 1, April 2016, hal 1-12.

Nopiyanthi, Ni Gusti Ayu Putu Elida, Wiarta, I Wayan, dan Suara, I Made. (2014). Penerapan Pendekatan Pembelajaran Kontekstual Berbantuan Media Lingkungan untuk Meningkatkan Aktivitas dan Hasil Belajar Ilmu Pengetahuan Alam Siswa Kelas IV SD Negeri 3 Abiantuwung Tahun Ajaran 2014/2015, E-Jurnal Mimbar PGSD Universitas Pendidikan Ganesha Jurusan PGSD Vol. 2, No. 1, 2014.

Prastowo, Andi.(2012). Panduan Kreatif Membuat Bahan Ajar Inovatif. Yogyakarta: Diva Press.

Pratama, Fendy Yogha, Pratiwi, Yuni, dan Andajani, Kusubakti. (2016). Pengembangan Bahan Ajar Menulis Teks Eksposisi Bermuatan Cinta Lingkungan dengan Strategi Pemodelan untuk Siswa Kelas VII SMP. Jurnal Pendidikan: Teori, Penelitian, dan Pengembangan Vol. 1, No. 3, Maret 2016, hal 448-462. 
Pratiwi, Sitoresmi Atika. (2015). Pengembangan Bahan Ajar Mengacu Kurikulum 2013 Subtema Jenis-Jenis Pekerjaan untuk Siswa Kelas IV Sekolah Dasar. Jurnal INDI (Inovasi Didaktik) Vol.1, No.1, Mei 2015, hal 14-34.

Purwanto. (2010). Evaluasi Hasil Belajar. Yogyakarta: Pustaka Pelajar.

Puspita, A.M.I. (2016). Peningkatan Hasil Belajar Siswa Berbantuan Buku Teks Berbasis Kontekstual Untuk Siswa Kelas II Sekolah Dasar. Jurnal Teori, Penelitian, dan Pengembangan, 1 (10), 1880 - 1883, Malang: Pascasarjana Universitas Negeri Malang

Puspita. A. M. I. (2018). Pengaruh Penerapan Pendekatan Kontekstual Terhadap Aktivitas dan Hasil Belajar Siswa di SDN I Campurdarat. Jurnal Dewantara Vol. 4, No.1, Maret 2018, hal 33-45. Trenggalek: STKIP PGRI Trenggalek . (2012). Evaluasi Hasil Belajar. Yogyakarta : Pustaka Pelajar.

Sanjaya, Wina. (2016). Strategi Pembelajaran Berorientasi Standar Proses Pendidikan. Jakarta: Prenada Media Grup.

Sariningsih, Ratna. (2014). Pendekatan Kontekstual untuk Meningkatkan Kemampuan Pemahaman Matematis Siswa SMP. Jurnal Ilmiah Program Studi Matematika STKIP Siliwangi Bandung Vol. 3, No.2, September 2014, hal 150-163.

Sari, Ririn Kurnila dan Nuryadi. (2014). Upaya Meningkatkan Motivasi dan Prestasi Pembelajaran Matematika dengan Pendekatan CT Siswa Kelas VII SMP. Jurnal AgriSains Vol. 5, No. 1, Mei 2014, hal 87-101.

Setiawan, Mohammad Arfi, Dasna, I Wayan, dan Marfu'ah, Siti. (2016). Pengaruh Bahan Ajar Multimedia Terhadap Hasil Belajar Dan Persepsi Mahasiswa Pada Matakuliah Kimia Organik I. Jurnal Pendidikan: Teori, Penelitian, dan Pengembangan Vol. 1, No. 4, April 2016, hal 746-751.

Sugiyono. (2014). Metode Penelitian Kuantitatif, Kualitatif, dan R\&D. Bandung: Alfabeta.

Suprijono, Agus. (2012). Cooperative Learning:Teori dan Aplikasi Paikem. Yogyakarta: Pustaka Pelajar.

Suyono. (2009). Pembelajaran Efektif dan Produktif Berbasis Literasi: Analisis Konteks, Prinsip, dan Wujud Alternatif Strategi Implementasinya di Sekolah. Jurnal Bahasa dan Seni Vol. 37, No. 2, Agustus 2009, hal 203-217.

Syahriyani, Alfi. (2010). Optimalisasi Budaya Literasi Di Kalangan Mahasiswa: Upaya Meretas Komunikasi Global. Jurnal UI Untuk Bangsa Seri Sosial dan Humaniora Vol. 1, Desember 2010, hal 67-78.

Trianto. (2007). Model Pembelajaran Terpadu dalam Teori dan Praktik. Jakarta : Prestasi Pustaka Publisher.

(2010). Mendesain Model Pembelajaran Inovatif Progresif. Jakarta: Kencana Predana Media Group.

Unesco. (2014). "Education for All 2000 Assessment."

Wardhana, Yana. (2010). Teori Belajar dan Mengajar. Bandung: Pribumi Mekar. 